\title{
Involvement of Hippocampal Jun-N Terminal Kinase Pathway in the Enhancement of Learning and Memory by Nicotine
}

\author{
Justin W Kenney', Cédrick Florian' ${ }^{2}$, George S Portugal', Ted Abel' ${ }^{2}$ and Thomas J Gould*,' \\ 'Department of Psychology, Temple University, Philadelphia, PA, USA; '2Department of Biology, University of Pennsylvania, Philadelphia, PA, USA
}

\begin{abstract}
Despite intense scrutiny over the past 20 years, the reasons for the high addictive liability of nicotine and extreme rates of relapse in smokers have remained elusive. One factor that contributes to the development and maintenance of nicotine addiction is the ability of nicotine to produce long-lasting modifications of behavior, yet little is known about the mechanisms by which nicotine alters the underlying synaptic plasticity responsible for behavioral changes. This study is the first to explore how nicotine interacts with learning to alter gene transcription, which is a process necessary for long-term memory consolidation. Transcriptional upregulation of hippocampal jun- $N$ terminal kinase I (JNKI) mRNA was found in mice that learned contextual fear conditioning (FC) in the presence of nicotine, whereas neither learning alone nor nicotine administration alone exerted an effect. Furthermore, the upregulation of JNKI was absent in $\beta 2$ nicotinic receptor subunit knockout mice, which are mice that do not show enhanced learning by nicotine. Finally, hippocampal JNK activation was increased in mice that were administered nicotine before conditioning, and the inhibition of JNK during consolidation prevented the nicotine-induced enhancement of contextual FC. These data suggest that nicotine and learning interact to alter hippocampal JNKI gene expression and related signaling processes, thus resulting in strengthened contextual memories. Neuropsychopharmacology (2010) 35, 483-492; doi:I0.1038/npp.2009. I53; published online 23 September 2009
\end{abstract}

Keywords: hippocampus; acetylcholine; MAPK; addiction; learning; gene transcription

\section{INTRODUCTION}

The use of tobacco products results in 5.4 million deaths each year worldwide (WHO, 2008). In the United States, only $4.7 \%$ of the 15.7 million Americans who attempt to quit each year are successful (CDC, 2002) as the large majority of attempts to quit end in relapse even after prolonged abstinence (Piasecki, 2006). The persistence of tobacco use suggests that nicotine, the primary component of tobacco responsible for its addictive properties (USDHHS, 1988), produces long-lasting changes in behavior. However, nicotine has long been recognized as a weak primary reinforcer compared with other drugs of abuse, such as cocaine or amphetamine (Chaudhri et al, 2006). The discrepancy between the relatively weak reinforcing effects of nicotine and its high addictive liability suggests that factors beyond reinforcement and reward must also contribute to nicotine addiction.

One factor that could contribute to the high addiction rate associated with nicotine is its ability to alter hippocampusdependent learning and synaptic plasticity (Kenney and Gould, 2008a). The hippocampus gates the flow of novelty and reward-related information to the nucleus accumbens

*Correspondence: Dr TJ Gould, Department of Psychology, Weiss Hall, Temple University, Philadelphia, PA 19122, USA, Tel: + I (215) 204-7495, Fax: + I (2I5) 204-5539, E-mail: tgould@temple.edu

Received 22 June 2009; revised 21 July 2009; accepted 25 August 2009
(Grace et al, 2007), and smoking-related cues change hippocampal activity in smokers (Franklin et al, 2007). Consolidation of long-term memories that underlie longlasting behavioral changes requires gene transcription and synthesis of new proteins (Hernandez and Abel, 2008; Alberini, 2009). Although learning and nicotine administration can independently alter gene transcription (Greenberg et al, 1986; Impey et al, 1998; Li et al, 2004), it is unknown whether learning and nicotine interact at the transcriptional level to produce a novel pattern of gene expression potentially modifying memory consolidation.

Contextual fear conditioning (FC) has proven to be a fruitful model to explore the effects of nicotine on hippocampus-dependent learning and memory, as the neurobiological underpinnings of this paradigm have been the subject of intense investigation (Fanselow and Poulos, 2005; Sigurdsson et al, 2007). In contextual FC, subjects must learn contextual information and then form an association between the context and a shock. Contextual learning involves forming a multimodal representation of the context, whereas context-shock learning is a form of Pavlovian conditioning in which the context-conditioned stimulus comes to elicit a fear-related unconditioned response after pairing with a shock-unconditioned stimulus (Rudy et al, 2004; Fanselow and Poulos, 2005). A study that separated contextual learning from context-shock association across days showed that nicotine enhances contextual learning and not context-shock learning (Kenney and 
Gould, 2008b), and that the hippocampus has been identified as integral for this enhanced contextual learning (Davis et al, 2007); these effects of nicotine are not due to generalized changes in anxiety because cued FC, which is a hippocampus-independent form of FC (Kim and Fanselow, 1992), is unaltered by nicotine (Gould and Wehner, 1999; Gould et al, 2004). This enhancement of contextual learning is long lasting (Gould and Higgins, 2003) and is dependent on high-affinity $\beta 2$-subunit containing $\mathrm{nAChRs}$ in the hippocampus (Davis et al, 2007) and activation of extracellular regulated kinase 1/2 (ERK1/2) of the mitogenactivated protein kinase (MAPK) family during acquisition (Raybuck and Gould, 2007). However, the molecular mechanisms responsible for consolidation of this nicotineenhanced memory are unknown.

Given the involvement of MAPKs in the consolidation of learning and memory (Sweatt, 2004), the central role of the hippocampus in contextual FC (Kim and Fanselow, 1992) and preliminary microarray data, suggesting that FC in the presence of nicotine alters the expression of certain members of the MAPK family (unpublished observations by Gould and Abel), nicotine and learning may interact to drive changes in hippocampal MAPK gene expression and activity that underlie the enhancement of contextual FC by nicotine. In this study, we show that acquisition of contextual FC in the presence of nicotine results in a different transcriptional profile for c-jun $\mathrm{N}$-terminal kinase 1 (JNK1) mRNA in the hippocampus during consolidation. Furthermore, we identify a critical nAChR subunit involved in the increase in JNK1 mRNA transcription, and show that activation of hippocampal JNK during consolidation is necessary for the enhancement of contextual FC by nicotine.

\section{MATERIALS AND METHODS}

\section{Animals}

Subjects were adult (8-12 weeks) male C57BL/6J (B6) or male and female $\beta 2$ nAChR knockout (KO) and wild-type (WT) mice backcrossed to a C57BL/6 background for at least seven generations. $\beta 2 \mathrm{nAChR} \mathrm{KO}$ and WT mice were bred from heterozygous mice and genotyped using PCR (Xu et al, 1999). Original breeding pairs were generously provided by $\mathrm{Dr}$ Arthur Beaudet at Baylor College of Medicine. Group housed mice (two to four per cage) and mice singly housed after surgical procedures had ad libitum access to food and water. The procedures were approved by the Temple University Institutional Animal Care and Use Committee and are in accordance with the National Institutes of Health Guidelines for the care and use of laboratory animals.

\section{Contextual FC}

Training and testing of contextual FC occurred in four identical Plexiglas $\left(26.5 \times 20.4 \times 20.8 \mathrm{~cm}^{3}\right)$ conditioning chambers housed in sound-attenuating boxes (Med Associates, St Albans, VT). Chamber floors were metal bars $(0.20 \mathrm{~cm}$ in diameter) spaced $1.0 \mathrm{~cm}$ apart connected to a shock generator and scrambler (Med Associates, Model ENV-414). Ventilation fans were mounted on the sides of each box to provide background noise and air exchange and each box was illuminated from above by a 4-Watt light bulb. Stimuli administration was controlled by a PC running LabView software.

For all behavioral procedures, freezing (defined as the lack of all movement aside from respiration) served as the dependent measure, and was assessed using a time sampling procedure: mice were observed for $1 \mathrm{~s}$ every $10 \mathrm{~s}$ and scored as either freezing or active. FC data are presented as the percentage of 1-s bins in which mice were scored as freezing.

The behavioral procedure has been described previously (Davis et al, 2006). Briefly, on training day, the mice were placed into the conditioning chambers and were allowed to explore for a 148-s baseline period. A 2-s, $0.57-\mathrm{mA}$ footshock was then administered after which immediate freezing was scored for $120 \mathrm{~s}$; the first footshock was followed by another footshock $148 \mathrm{~s}$ later. Mice remained in the chambers $30 \mathrm{~s}$ after the second footshock before being removed from their home cage. In an experiment to test whether the level of conditioning altered gene expression, mice were conditioned with either two or five shock presentations. Mice that received five shocks were given a 148 -s baseline period, followed by five 2 -s, $0.57-\mathrm{mA}$ footshocks with a 148-s inter-stimulus interval; mice that received two footshocks were only administered the second and fourth of the five footshocks, but the amount of time spent in the chambers was the same as those administered five shocks. Testing occurred $24 \mathrm{~h}$ later as described above.

\section{Surgery}

Mice anesthetized with isoflurane gas (5\% induction, 2-3\% maintenance) were placed in a stereotaxic apparatus (David Kopf Instruments, Tujunga, CA). The scalp was incised and retracted to expose the skull, and the lambda and bregma were aligned in the same horizontal plane. Two 21-gauge holes were drilled into the skull, and bilateral stainless steel guide cannulae (C232G, 22 gauge; Plastics One, Roanoke, VA) were inserted and fixed to the skull with dental cement. The dummy cannulae (C232DC; Plastics One) were inserted into the guide cannulae to prevent clogging. The dorsal hippocampus coordinates were as follows: posterior to bregma: $-1.7 \mathrm{~mm}$; mediolateral: $\pm 1.5 \mathrm{~mm}$; and ventral to skull surface: $-2.3 \mathrm{~mm}$. The mice were allowed at least 5 days to recover before behavioral procedures began. Placements were verified as described previously (Davis et al, 2007). One mouse with incorrect placements was excluded from statistical analysis.

\section{Drugs and Administration}

All drugs were purchased from Sigma-Aldrich (St Louis, MO). Nicotine hydrogen tartrate salt (reported as freebase: $0.09 \mathrm{mg} / \mathrm{kg}$, according to Gould and Higgins (2003)) was dissolved in physiological saline. Nicotine or saline was administered intraperitoneally $5 \mathrm{~min}$ before training and testing in contextual FC at an injection volume of $0.01 \mathrm{ml} / \mathrm{g}$ body weight. The 5-min pretreatment time point for nicotine was chosen because, in B6 mice, plasma levels of nicotine peak at $5 \mathrm{~min}$ after intraperitoneal administration with a half-life of $\sim 6 \mathrm{~min}$ (Petersen et al, 1984). 
SP600125 (10-20 $\mu \mathrm{M}$ according to Bevilaqua et al (2003)), which is an ATP-competitive inhibitor of JNK (Bennett et al, 2001), was dissolved in 0.1\% DMSO and administered by direct infusion into the dorsal hippocampus either $15 \mathrm{~min}$ before training or testing or $60 \mathrm{~min}$ after training in contextual FC. During infusion, the mice were gently restrained and the dummy cannulae were removed and replaced with 28-gauge infusion cannulae. SP600125 or vehicle was infused at a rate of $0.50 \mu \mathrm{l} / \mathrm{min}$ with an injection volume of $0.50 \mu \mathrm{l}$ per side. Infusion cannulae were attached to polyethylene tubing (PE50; Plastics One), connected to a 10- $\mu$ l Hamilton syringe (Reno, NV). Drug administration was controlled using a microinfusion pump (KDS 100; KD Scientific, New Hope, PA). Injection cannulae were left in place for $1 \mathrm{~min}$ after infusion to allow the drug to diffuse away from the cannula tip.

\section{RNA Extraction and Quantitative Real-Time Reverse Transcription-PCR}

Mice were killed either $30 \mathrm{~min}$ or $2 \mathrm{~h}$ after training in contextual FC (FC + Sal or FC + Nic) or after an equal time period after injection for home-cage control mice (No FC + Sal or No FC + Nic). Home-cage control mice were injected, returned to their home cage, and handled an equivalent amount of time as mice that were trained in FC. Whole hippocampi and cerebellum were rapidly dissected and immediately placed into RNALater (Sigma-Aldrich) and stored at $-80^{\circ} \mathrm{C}$. Tissue was then processed, and data were normalized as described previously (Vecsey et al, 2007). Briefly, tissue was homogenized in $1 \mathrm{ml}$ Trizol (Invitrogen, Carlsbad, CA), and total RNA was isolated and purified using the RNeasy system (Qiagen, Valencia, CA) and DNAse treatment. cDNA was generated from $1 \mu \mathrm{g}$ of total RNA per sample using RETROscript Kit (Ambion, Austin, TX). Quantitative reverse transcription (qRT-PCR) was performed using $11.5 \mu \mathrm{l} \mathrm{cDNA}, 1 \mu \mathrm{l}$ of $5 \mu \mathrm{M}$ primer solution, and $12.5 \mu \mathrm{l}$ Power SYBR Green PCR master mix. Reactions were carried out in the 7500 Fast Real-Time PCR System (Applied Biosystems, Austin, TX) with an initial activation by incubation at $50^{\circ} \mathrm{C}$ for $2 \mathrm{~min}$, followed by incubation at $95^{\circ} \mathrm{C}$ for $15 \mathrm{~min}$ and 40 subsequent cycles of $95^{\circ} \mathrm{C}$ for $15 \mathrm{~s}, 56^{\circ} \mathrm{C}$ for $30 \mathrm{~s}$, and $72^{\circ} \mathrm{C}$ for $30 \mathrm{~s}$. All qRT-PCRs were performed in triplicate. Primer sequences are listed in Supplementary Table S1. Threshold cycle (Ct) values were adjusted for efficiency and then normalized to four internal control genes, namely Hprt, Tubulin, Actin- $\gamma$, and Gapdh. Mean values obtained from triplicate experiments were then used to generate group statistics.

\section{Quantitative Western Blotting}

Nicotine-treated $\mathrm{B} 6$ mice were killed $1 \mathrm{~h}$ after training in contextual FC or after an equal time period after saline injection for home-cage control mice. Home-cage control mice were injected, returned to their home cage, and handled an equivalent amount of time as mice that were trained in FC. Both ventral and dorsal hippocampal tissues were separately homogenized in a lysis buffer containing $150 \mathrm{mM} \mathrm{NaCl}, 50 \mathrm{mM}$ Tris- $\mathrm{HCl} \mathrm{pH}$ 8.0, $1 \% \mathrm{NP} 40,0.5 \%$ sodium deoxycholate, and $0.1 \%$ SDS. Samples were then sonicated briefly, centrifuged, and supernatants collected, and total protein concentration determined using the Bradford Protein Assay (Bio-Rad, Hercules, CA). Equal amounts $(15 \mu \mathrm{g})$ of protein samples were loaded and separated by electrophoresis on $4-12 \%$ gradient polyacrylamide gels (Invitrogen). Gels were then electroblotted to PVDF membranes (Millipore, Billerica, MA). Membranes were blocked for $24 \mathrm{~h}$ in $1 \%$ BSA or $5 \%$ nonfat dry milk in TTBS (Tris $500 \mathrm{mM}, \mathrm{pH} 7.4, \mathrm{NaCl} 1.5 \mathrm{M}$, and $0.1 \%$ Tween 20). Blots were then incubated for $24 \mathrm{~h}$ with the following primary polyclonal antibodies: anti-pJNK ( $1: 5000$; Promega, Madison, WI; Cat. No. V7931) and anti-JNK (1:1000; BD Pharmingen, San Jose, CA; Cat. No.554285). Blots were rinsed in TTBS buffer and incubated for $3 \mathrm{~h}$ with goat-antirabbit or goat-anti-mouse secondary antibodies conjugated with horseradish peroxidase. The dilution of secondary antibody was $1: 1000$. After washing, an enhanced chemiluminescent detection method (ECL plus; Amersham Biosciences) was performed to develop filter signals. The Kodak film signals were digitally scanned and quantified using NIH Image J software. The membranes were then stripped using one 5-min wash of stripping buffer $(0.5 \mathrm{M} \mathrm{NaOH})$. The stripped membranes were washed thoroughly in TTBS, and immunoblotting was performed again with an antibody to anti- $\beta$-tubulin $(1: 20000$; Sigma-Aldrich; Cat. No. T4026).

\section{Statistical Analyses}

For qRT-PCR, mean Ct values obtained from experiments conducted in triplicate and log-scale values were used to conduct independent samples $t$-tests. Experimental groups (No FC + Nic, FC + Sal, or FC + Nic) were each individually compared with home-cage control mice (No FC + Sal) after separate qPCR runs. If the variance of comparison groups was unequal as determined by the Levene statistic, independent samples $t$-tests were conducted without the assumption of equal variance, otherwise equal variance was assumed. For western blotting experiments, independent samples $t$-tests were conducted. Contextual FC was analyzed using one or two-way ANOVAs where appropriate, and followed up with Tukey's HSD post hoc tests.

\section{RESULTS}

\section{Increase in JNK1 mRNA After FC in the Presence of Nicotine}

To explore whether acquiring FC in the presence of nicotine resulted in unique transcriptional regulation compared with training in the absence of nicotine, quantitative real-time RT-PCR was used to measure changes in hippocampal MAPK gene expression. Changes in ERK1 (MAPK3), ERK2 (MAPK1), ERK5 (MAPK7), JNK1 (MAPK8), JNK2 (MAPK9), JNK3 (MAPK10), and p38 (MAPK14) mRNA were examined $30 \mathrm{~min}$ after $\mathrm{FC}$ in $\mathrm{B} 6$ mice treated with saline $(\mathrm{FC}+\mathrm{Sal})$ or nicotine $(\mathrm{FC}+\mathrm{Nic})$ and in $\mathrm{B} 6$ mice that received similar injections but no conditioning (No FC + Sal or No FC+Nic, respectively); follow-up experiments examined JNK1 mRNA at $2 \mathrm{~h}$ after training. JNK1 mRNA in the hippocampus was upregulated $30 \mathrm{~min}$ after conditioning in the presence of nicotine compared with the No FC + Sal group $(t(20)=2.42, p=0.025$; Figure $1 \mathrm{a})$. 

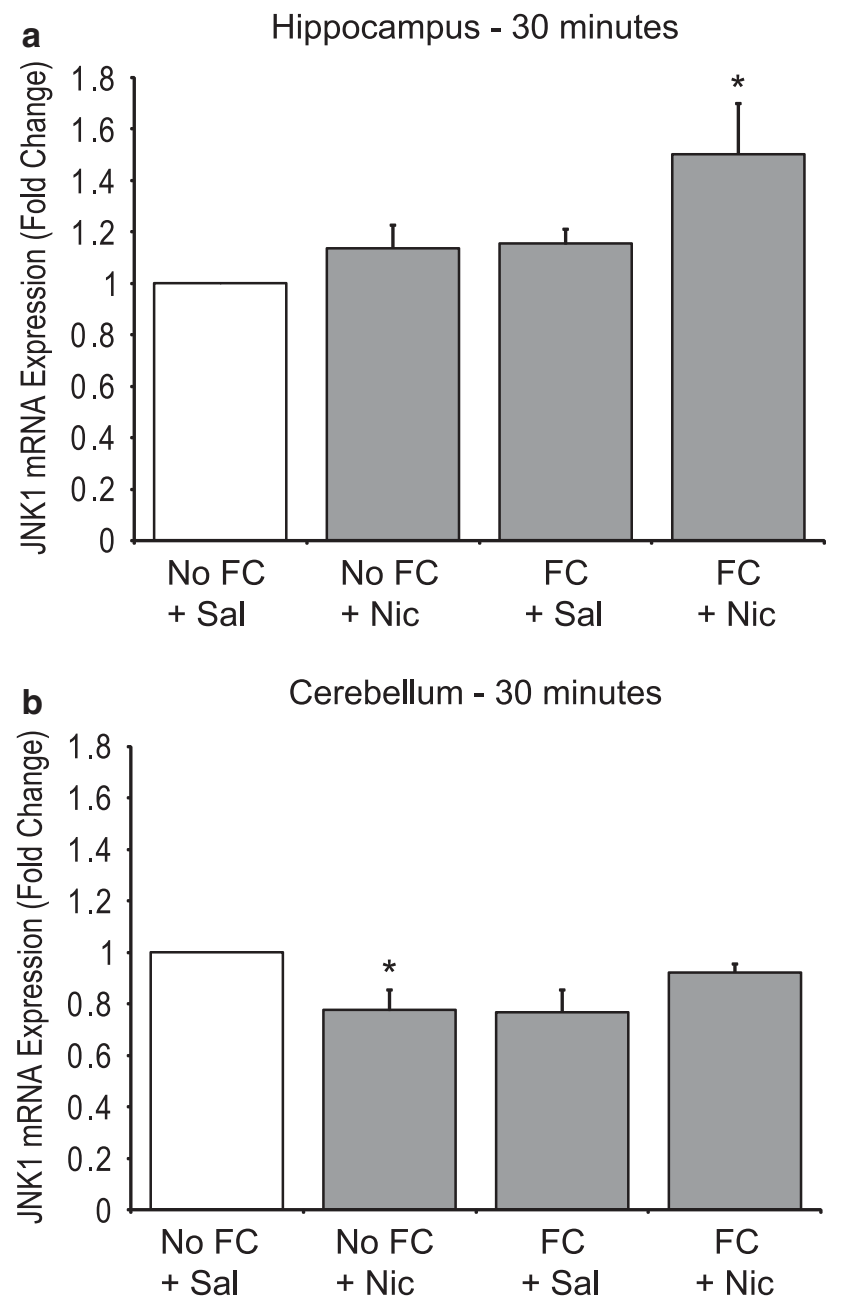

C

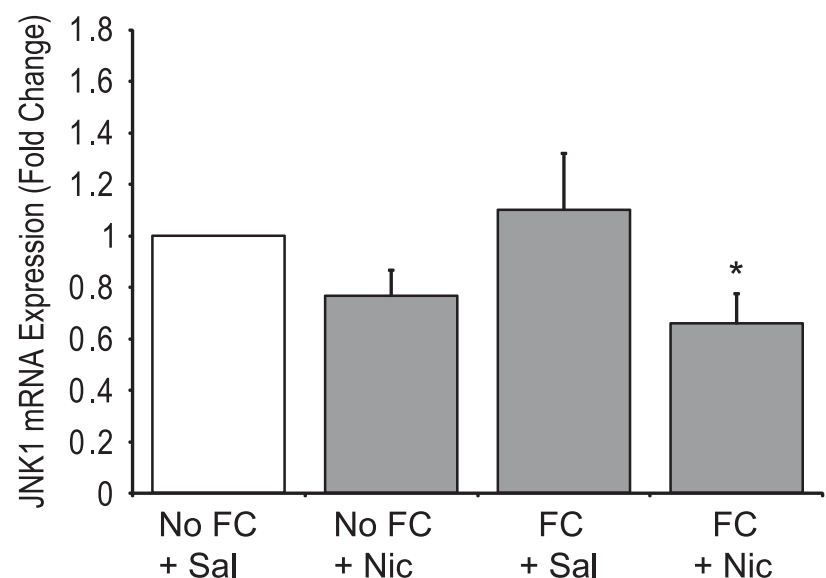

Figure I Upregulation of JNKI mRNA in the hippocampus of B6 mice 30 min after training in the presence of nicotine. (a) Regulation of JNKI mRNA in the hippocampus $30 \mathrm{~min}$ after training. JNKI mRNA was upregulated only in the group trained in the presence of nicotine (FC+Nic). (b) Regulation of JNKI mRNA in the cerebellum 30 min after training. JNKI was downregulated only in the group that received nicotine in their home cage (No FC + Nic). (c) Regulation of JNKI mRNA in the hippocampus $2 \mathrm{~h}$ after training. JNKI mRNA was downregulated only in B6 mice trained in the presence of nicotine. $* p<0.05$ compared with the respective home-cage saline group (No FC+ Sal). FC + Sal - trained saline. Error bars represent SEM, $n=|0-| \mid$.
Importantly, neither nicotine administration alone nor training alone altered JNK1 mRNA at this time point (Figure 1a). The cerebellum, similar to the hippocampus, expresses the $\beta 2 \mathrm{nAChR}$ subunit (Wada et al, 1989) that is involved in the effects of nicotine on contextual FC (Wehner et al, 2004; Davis and Gould, 2007). Thus, to test whether transcriptional changes generalized to an area not critically involved in the consolidation of contextual learning, JNK1 mRNA expression was measured in the cerebellum at the 30 -min time point. The only change in the cerebellum was the downregulation of JNK1 mRNA in the No FC+Nic group $(t(19)=2.11, p=0.049)$ and a marginal downregulation in the FC + Sal group $(t(19)=2.06$, $p=0.053$; Figure $1 \mathrm{~b}$ ), suggesting that the upregulation observed in the hippocampus of B6 mice trained in the presence of nicotine is not global. Interestingly, at $2 \mathrm{~h}$ after training, hippocampal JNK1 mRNA was downregulated in B6 mice trained in the presence of nicotine $(t(19)=2.33, p=0.031$; Figure $1 \mathrm{c})$. The fact that JNK1 mRNA was downregulated $2 \mathrm{~h}$ after training of nicotinetreated B6 mice suggests that the increase in JNK1 mRNA observed at $30 \mathrm{~min}$ may activate autoregulatory processes leading to downregulation.

ERK1, ERK2, ERK5, JNK2, JNK3, and p38 mRNA did not show the same pattern of regulation in the hippocampus at the 30-min time point as did JNK1 mRNA (Table 1). ERK2 mRNA was upregulated in the hippocampus after both nicotine administration alone $(t(12.8)=2.44, p=0.030)$ and training in the absence $(t(20)=2.69, p=0.014)$ or presence $(t(11.5)=3.22, p=0.008)$ of nicotine, and ERK5 mRNA was upregulated after nicotine administration alone $(t(20)=$ $2.53, p=0.020)$. There was no effect of any treatment on ERK1, JNK2, JNK3, or p38 mRNA expressions. Finally, training day behavioral activity in all B6 mice used for qRTPCR was examined to determine whether there were any differences in baseline and immediate freezing during acquisition of contextual FC due to nicotine administration (Supplementary Table S2); no significant differences were found.

If the enhancement of contextual FC by nicotine is the result of amplification of molecular mechanisms typically involved in the acquisition of the task, then using a training paradigm that results in increased contextual freezing should cause a similar increase in hippocampal JNK1 mRNA. However, if learning and nicotine interact to recruit molecular mechanisms that are not typically involved in the consolidation of contextual fear memories, then increasing contextual FC through stronger training should exert no effect on hippocampal JNK1 mRNA levels. To explore these two possibilities, B6 mice were trained with either two or five shocks, and hippocampal JNK1 mRNA was examined 30 min after training. A separate group of B6 mice were tested $24 \mathrm{~h}$ later for contextual freezing. Although increasing the number of shocks administered significantly increased contextual FC $24 \mathrm{~h}$ after training $(t(17)=3.20, p=0.005)$, there was no concomitant increase in hippocampal JNK1 mRNA 30 min after training (Table 2). This suggests that the increase in JNK1 mRNA in the hippocampus after learning in the presence of nicotine is due to a unique interaction between nicotine and learning and not due to an increase in the contribution of processes typically involved in memory consolidation. 
Previous work has found that $\beta 2 \mathrm{KO}$ mice show normal FC, but do not show enhancement of contextual FC by nicotine (Caldarone et al, 2000; Davis and Gould, 2007). Therefore, one would predict that nicotine would increase JNK1 mRNA expression in the hippocampus $30 \mathrm{~min}$ after training in WT mice, but not in $\beta 2 \mathrm{KO}$ mice. Indeed, JNK1 mRNA was upregulated in the hippocampus of WT mice conditioned in the presence of nicotine $(t(28)=2.24$, $p=0.033$ ), whereas no change occurred in $\beta 2 \mathrm{KO}$ mice

Table I RT-qPCR for all MAPK Genes Examined in the Hippocampus 30 min After Training in Contextual Fear Conditioning in the Absence or Presence of Nicotine or an Equal Amount of Time Following Nicotine Administration

\begin{tabular}{|c|c|c|c|c|}
\hline mRNA & Experimental group & Fold change & +SEM & -SEM \\
\hline \multirow[t]{4}{*}{ ERKI } & No FC+Sal & 1.00 & & \\
\hline & No FC+Nic & 1.22 & 0.08 & 0.08 \\
\hline & $\mathrm{FC}+\mathrm{Sal}$ & 1.15 & 0.09 & 0.08 \\
\hline & $\mathrm{FC}+\mathrm{Nic}$ & 1.23 & 0.06 & 0.05 \\
\hline \multirow[t]{4}{*}{ ERK2 } & No FC+Sal & 1.00 & & \\
\hline & No FC+Nic & $1.37 *$ & 0.06 & 0.06 \\
\hline & $\mathrm{FC}+\mathrm{Sal}$ & $1.39 *$ & 0.09 & 0.08 \\
\hline & $\mathrm{FC}+\mathrm{Nic}$ & $1.48 *$ & 0.05 & 0.05 \\
\hline \multirow[t]{4}{*}{ ERK5 } & No FC+Sal & 1.00 & & \\
\hline & No FC+Nic & $1.67 *$ & 0.12 & 0.11 \\
\hline & $\mathrm{FC}+\mathrm{Sal}$ & 1.69 & 0.16 & 0.14 \\
\hline & $\mathrm{FC}+\mathrm{Nic}$ & 1.34 & 0.12 & 0.11 \\
\hline \multirow[t]{4}{*}{$|N K|^{a}$} & No FC+Sal & 1.00 & & \\
\hline & No FC+Nic & 1.14 & 0.09 & 0.08 \\
\hline & $\mathrm{FC}+\mathrm{Sal}$ & 1.16 & 0.06 & 0.05 \\
\hline & $\mathrm{FC}+\mathrm{Nic}$ & $1.50 *$ & 0.20 & 0.17 \\
\hline \multirow[t]{4}{*}{ JNK2 } & No FC+Sal & 1.00 & & \\
\hline & No FC+Nic & 1.06 & 0.07 & 0.07 \\
\hline & $\mathrm{FC}+\mathrm{Sal}$ & 0.97 & 0.09 & 0.08 \\
\hline & $\mathrm{FC}+\mathrm{Nic}$ & 1.05 & 0.07 & 0.06 \\
\hline \multirow[t]{4}{*}{ JNK3 } & No FC+Sal & 1.00 & & \\
\hline & $\mathrm{No} F C+\mathrm{Nic}$ & 0.74 & 0.12 & 0.10 \\
\hline & $\mathrm{FC}+\mathrm{Sal}$ & 0.56 & 0.17 & 0.13 \\
\hline & $\mathrm{FC}+\mathrm{Nic}$ & 0.59 & 0.12 & 0.10 \\
\hline \multirow[t]{4}{*}{ p38 } & No FC+Sal & 1.00 & & \\
\hline & No FC+Nic & 0.90 & 0.07 & 0.07 \\
\hline & $\mathrm{FC}+\mathrm{Sal}$ & 1.06 & 0.07 & 0.07 \\
\hline & $\mathrm{FC}+\mathrm{Nic}$ & 1.02 & 0.06 & 0.06 \\
\hline
\end{tabular}

No FC+Sal, home-cage saline, No FC+Nic, home-cage nicotine, FC+Sal, trained saline, FC+Nic, trained nicotine; $n=10-1$ I for each group. * $p<0.05$ compared with No FC+Sal group.

${ }^{\mathrm{a} D a t a}$ are presented in Figure 1.
(Figure 2). This result strongly suggests that the effects of nicotine at $\beta 2$-subunit containing nAChRs in the hippocampus are necessary for the upregulation of JNK1 mRNA associated with enhanced contextual FC.

\section{Blocking JNK Activation in the Hippocampus Prevents Consolidation of the Nicotine-Enhanced Contextual Fear Memory}

If the upregulation of JNK1 mRNA in the hippocampus is related to the enhancement of contextual FC by nicotine, then blocking the activation of the JNK1 protein in the hippocampus should prevent the nicotine-induced enhancement. Initially, we examined the effects of a JNK inhibitor, SP600125 (SP; 10-20 $\mu \mathrm{M}$ ), infused into the dorsal hippocampus before training, $60 \mathrm{~min}$ after training, or before testing to establish a dose to use in conjunction with systemic nicotine. Infusion of SP alone before training or before testing exerted no effect on contextual FC (Figure 3a, inset). However, infusion of SP into the hippocampus 60 min after training dose dependently decreased contextual FC $(\mathrm{F}(3,30)=8.66, \quad P<0.001)$; post hoc tests showed that B6 mice infused with $20 \mu \mathrm{M}$ of SP, but not with 10 or $15 \mu \mathrm{M}$ of SP, showed a deficit in contextual FC compared with vehicle-infused B6 mice $(p<0.05$; Figure $3 \mathrm{a})$. Therefore, the $15 \mu \mathrm{M}$ dose of SP was used as a subthreshold dose in experiments in which nicotine was coadministered with SP.

Infusion of $15 \mu \mathrm{M}$ SP before training or testing exerted no effect on the enhancement of contextual FC by nicotine (Figure $3 b$ ). There was a main effect of systemic drug

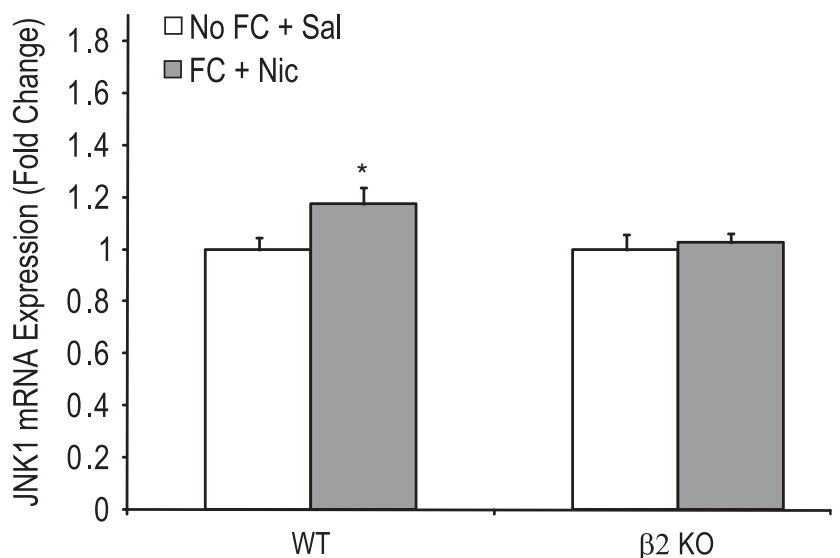

Figure 2 Lack of upregulation of JNKI mRNA in the hippocampi of $\beta 2$-subunit nAChR KO mice trained in the presence of nicotine (FC + Nic). Thirty minutes after conditioning in the presence of nicotine JNKI mRNA was upregulated in WT but not in $\beta 2 \mathrm{KO}$ mice. $* \mathrm{p}<0.05$ compared with the respective home-cage saline group (No FC+ Sal). Error bars represent SEM, $n=14-15$.

Table 2 Percent Freezing and RT-qPCR Data for Hippocampal JNKI mRNA 30 min After Training With Two or Five Shocks, n=9-I0

\begin{tabular}{|c|c|c|c|c|c|c|}
\hline Experimental group & Percent context freezing & \pm SEM & mRNA & mRNA fold change & +SEM & - SEM \\
\hline 2 Shocks & 38.1 & 5.2 & JNKI & 1.00 & 0.07 & 0.06 \\
\hline 5 Shocks & $55.7^{*}$ & 5.0 & & 0.99 & 0.08 & 0.08 \\
\hline
\end{tabular}

* $p<0.05$ compared with 2 shock group. 
administration on contextual freezing in both experiments $(\mathrm{F}(1,30)=24.7, p<0.001$ and $\mathrm{F}(1,31)=28.8, p<0.001$; for SP infusions before training and testing, respectively), and post hoc tests confirmed that B6 mice that were administered nicotine, regardless of infusion condition, froze significantly more than did B6 mice that were administered systemic saline and infused with vehicle or $15 \mu \mathrm{M}$ SP before training or testing $(p<0.05)$. In contrast, SP infused $60 \mathrm{~min}$ after training blocked the enhancement of contextual FC by nicotine (Figure $3 \mathrm{~b}$ ); A $2 \times 2$ ANOVA showed an interaction between systemic drug administration and hippocampal infusion $(\mathrm{F}(1,29)=8.41, p=0.007)$. Post hoc tests confirmed that in vehicle-infused B6 mice, systemic nicotine administration enhanced contextual FC compared with salinetreated B6 mice $(p<0.05)$, but nicotine-treated B6 mice infused with $15 \mu \mathrm{M}$ SP did not show enhancement. To determine whether the drug treatments altered freezing during acquisition, both baseline and immediate freezing were examined. As B6 mice infused with SP after conditioning and before testing were subjected to identical manipulations during training, these groups were collapsed for analysis. There was no effect of systemic nicotine administration on baseline or immediate freezing in B6 mice not infused during training (data not shown). There was a main effect of nicotine administration in baseline freezing in mice infused before training $(\mathrm{F}(1,30)=2.88$, $p=0.024$; data not shown) and no effect on immediate freezing. However, post hoc analysis showed only a significant difference between mice treated with SP and nicotine and mice treated with SP and saline; there were no groups significantly different from the control group. This result and the findings that there were no other training-day differences for the other experiments suggest that nicotine alters consolidation but not immediate stages of acquisition. Thus, JNK activation in the hippocampus is necessary for the consolidation, but not for the acquisition or retrieval, of a nicotine-enhanced contextual memory.

\section{Learning in the Presence of Nicotine Results in an Increase in Hippocampal pJNK1}

To confirm the behavioral pharmacological data that suggest that JNK activation mediates the enhancement of learning by nicotine, western blots examining changes in hippocampal pJNK, the active form of JNK, were performed. B6 mice were either administered saline and returned to their home cage or were administered nicotine and trained in contextual FC. The hippocampal tissue was dissected $1 \mathrm{~h}$ after training and divided into dorsal and ventral sections of the hippocampus. As blocking the active form of JNK through SP infusions made into the dorsal hippocampus were capable of blocking consolidation of the nicotineenhanced contextual fear memory, we hypothesized that pJNK1 would be increased in the dorsal hippocampus. Western blots indicate that pJNK1 was increased in the dorsal $(t(9)=3.12, p=0.014)$ but not in the ventral hippocampus (Figure 4). Total dorsal hippocampal JNK1 was also examined at the 1 -h time point, and no difference was found between the untrained saline B6 mice and B6 mice trained in the presence of nicotine (No FC+Sal: $100 \pm 27.4$, FC + Nic: $88.2 \pm 13.1$ ).
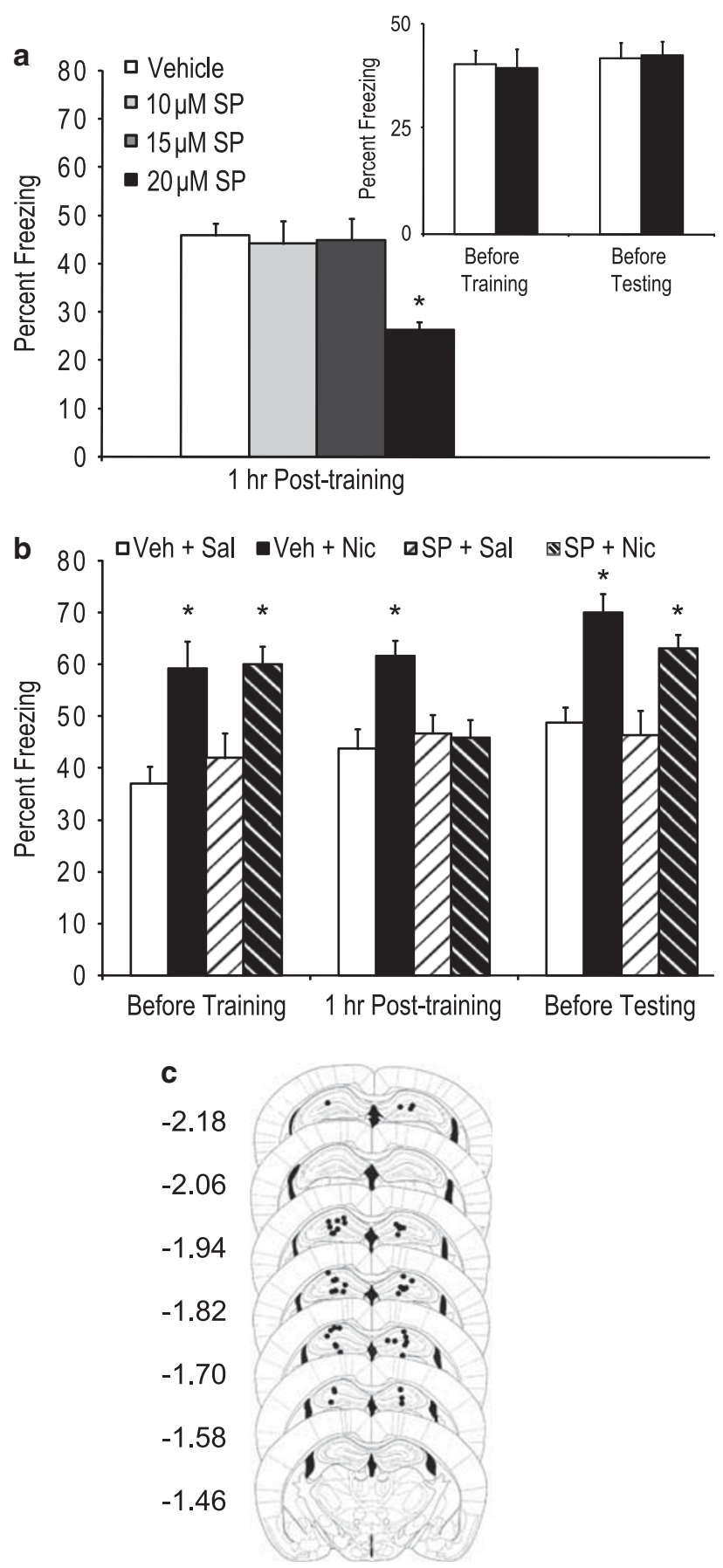

Figure 3 Pharmacological inhibition of dorsal hippocampal JNK activation at consolidation prevents the enhancement of contextual fear conditioning by nicotine. (a) Infusion of SP into the hippocampus before training or testing (inset), or $60 \mathrm{~min}$ after training in contextual fear conditioning, no nicotine was administered $(n=6-12)$. The $20 \mu \mathrm{M}$ dose of SP resulted in a deficit in fear conditioning only when given 60 min after training compared with vehicle-infused mice. (b) Infusion of a subthreshold dose of SP $(15 \mu \mathrm{M})$ into the hippocampus before training $(n=8-9)$ or testing $(n=8-10)$ exerted no effect on the enhancement of contextual fear conditioning by nicotine $(0.09 \mathrm{mg} / \mathrm{kg})$. In contrast, SP infusions (I $5 \mu \mathrm{M})$ into the hippocampus $60 \mathrm{~min}$ after training in contextual fear conditioning blocked the nicotine-induced enhancement $(n=8-9)$. (c) Hippocampus infusions sites for the systemic nicotine and post-training SP infusion study; figures modified from Paxinos and Franklin (200I). $* 0<0.05$ compared with vehicle-infused B6 mice or vehicle/SP-infused + saline-treated B6 mice. Error bars represent SEM. 
a

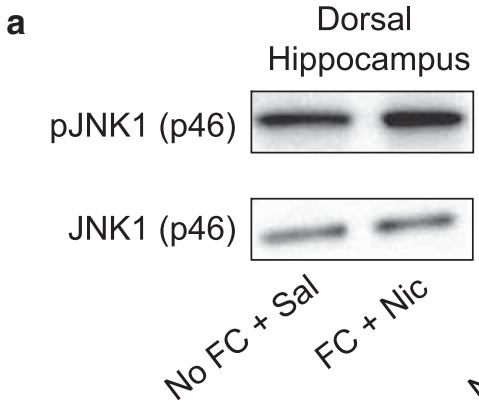

Hippocampus

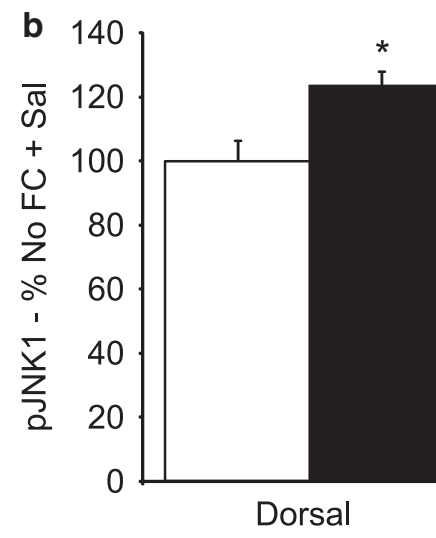

Ventral Hippocampus
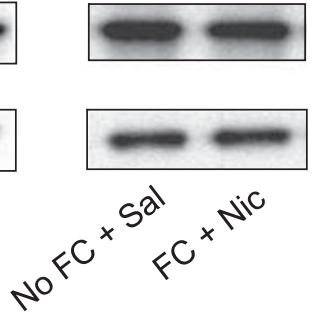
no

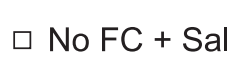

- $\mathrm{FC}+\mathrm{NiC}$ campus of mice trained with nicotine, suggesting that the upregulation seen at $30 \mathrm{~min}$ after training could lead to a later period of suppressed JNK1 mRNA expression. The interactive effects of nicotine and learning were specific to JNK1 mRNA expression as other members of the MAPK family did not show the same pattern of transcriptional regulation. The nicotine-associated increase in JNK1 signaling may contribute to enhanced consolidation of contextual memories; during consolidation, hippocampal infusion of a dose of a JNK inhibitor subthreshold for impairing conditioning blocked the nicotine-induced enhancement, and pJNK1 levels in the dorsal hippocampus were increased after learning in the presence of nicotine. Given that pJNK1 is the active form of JNK1, an increase in pJNK1 suggests that the downstream effectors of JNK1 are also being activated and likely contribute to the nicotineinduced enhancement of learning and memory. Taken together, these data suggest that JNK1 signaling mediates the nicotine-induced enhancement of hippocampal synaptic plasticity that underlies the enhanced contextual fear memory.

Interestingly, JNK may also have a role in the consolidation of contextual fear memories in the absence of drug, as post-training hippocampal administration of a higher dose of a JNK inhibitor that inactivates all three JNK isoforms produced a deficit; an effect only previously observed with passive avoidance (Bevilaqua et al, 2003). Given that a subthreshold dose of a JNK inhibitor in the hippocampus blocked the consolidation of a nicotine-enhanced contextual fear memory, nicotine may increase the contribution of JNK to FC through an upregulation of the JNK1 gene. What is particularly intriguing is that the upregulation of JNK1 mRNA was unique to the enhancing effect of nicotine on contextual FC, as a stronger training protocol that produced similar levels of conditioning as seen in nicotine-treated mice did not result in such an upregulation. Thus, the increased JNK1 mRNA after learning in the presence of nicotine may be a mechanism through which nicotine usurps the neural substrates of learning and memory.

Although the increase in JNK1 mRNA in the hippocampus $30 \mathrm{~min}$ after training in the presence of nicotine might suggest that this treatment should also result in an increase in the JNK1 protein, no increase in the JNK1 protein was found at the $1-h$ post-training time point. This may be because of the fact that qRT-PCR is more sensitive in detecting small changes in mRNA levels than is western blotting at detecting small changes in protein levels. Alternatively, it may be the case that the 1-h time point does not coincide with the peak of protein production after an increase in JNK1 mRNA levels. Although JNK1 mRNA levels decrease between $30 \mathrm{~min}$ and $2 \mathrm{~h}$ after training in the presence of nicotine, an increase in the JNK1 protein may occur later than $1 \mathrm{~h}$ after training because mRNA half-life tends to be shorter than protein half-life, although there is considerable variability in these parameters across proteins (Hargrove and Schmidt, 1989). An extensive time course for changes in JNK1 mRNA and JNK1 protein levels after training in the presence of nicotine could further elucidate this issue.

The nicotine-induced enhancement of contextual learning (Kenney and Gould, 2008b) may have an important role in the high addictive liability of nicotine. Contextual stimuli 
have an integral role in the development and maintenance of nicotine self-administration (Caggiula et al, 2002); for example, exposure to contextual cues previously associated with nicotine administration increased drug seeking (Crombag et al, 2008; Diergaarde et al, 2008), and such contextual stimuli both delay the extinction of nicotine self-administration and are involved in reinstatement of self-administration in rats (Wing and Shoaib, 2008). Furthermore, smokers reported greater amelioration of cravings when nicotine-associated cues were given along with nicotine than when either nicotine or cues were presented alone (Rose et al, 2000). Thus, the ability of nicotine to increase the strength of contextual memories may facilitate the development of nicotine addiction and increase the likelihood of context-induced relapse during quit attempts.

It has been established that both the hippocampus and $\beta 2$-containing nAChRs are critically involved in the effects of nicotine on contextual FC (Wehner et al, 2004; Davis and Gould, 2007; Davis et al, 2007). Mechanisms mediating the memory-enhancing effect downstream from nAChRs are only now beginning to be elucidated (Figure 5). The effects of nicotine at nAChRs may interact with NMDA receptormediated processes to alter contextual FC (Gould and Lewis,

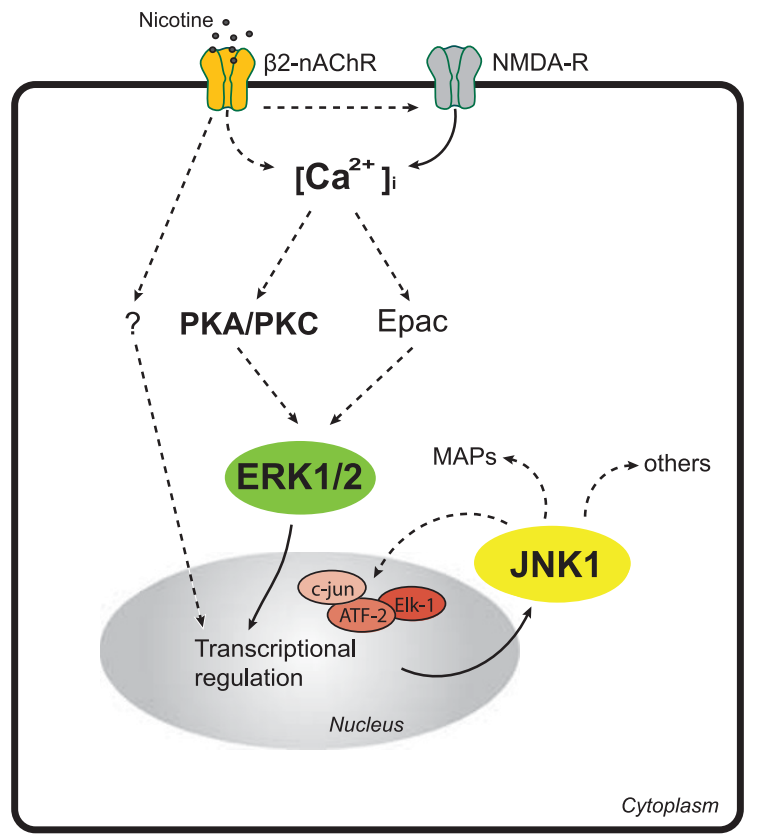

Figure 5 A proposed cell-signaling cascade underlying the enhancement of contextual fear conditioning by nicotine. Nicotine acts at high-affinity $\beta 2$ subunit containing $\mathrm{nAChRs}$ to directly or indirectly gate calcium through NMDA receptors. Increased intracellular calcium may activate PKC, PKA, or Epac, which are all known to stimulate ERK activation. ERK is known to activate gene transcription through various transcription factors. Alternatively, an unknown cascade may be recruited after nicotine binding to $\beta 2$ subunit containing $\mathrm{nAChRs}$. Activation of transcription factors may mediate an increase in JNKI mRNA transcription and lead to an increase in the activation of JNKI. Increased JNKI activation may lead an enhanced memory through another round of transcriptional activity, activation of microtubule-associated protein (MAP), or other unknown actions. Dashed lines represent hypothetical signaling pathways that nicotine may modify to enhance contextual fear conditioning, and solid lines represent pathways that nicotine is known to modulate to enhance contextual fear conditioning.
2005). In support of nicotinic and glutamatergic interaction, glutamate receptors and nAChRs colocalize to pyramidal cells in the cortex (Levy and Aoki, 2002); hippocampal pyramidal cells have yet to be examined, but nAChRs have been found to functionally alter glutamate sensitive neurons in the hippocampus (Ji et al, 2001; Alkondon et al, 2003). Activation of nicotinic receptors may directly lead to post-synaptic depolarization and removal of the NMDA magnesium block, thereby allowing an influx of calcium. Alternatively, $\beta 2$-containing nAChRs are themselves capable of gating calcium, the extent of which is dependent on the specific stoichiometry of the receptor (Tapia et al, 2007). Calcium influx can lead to an increase in the activation of cell signaling molecules such as protein kinase C, cAMP-dependent protein kinase (PKA), and/or exchange protein activated by cAMP, which are capable of phosphorylating ERK (Roberson et al, 1999; Gelinas et al, 2008); a kinase implicated in contextual FC (Sweatt, 2004) and the enhancement of contextual FC by nicotine (Raybuck and Gould, 2007), and activated by nicotine (Valjent et al, 2004). Relevant to the present findings, ERK activates various transcription factors such as CREB, Sp1, and c-myc (Turjanski et al, 2007) that may regulate JNK1 mRNA transcription. Thus, the effects of nicotine on high-affinity hippocampal nAChRs could lead to an ERK-mediated increase in JNK1 mRNA expression. The suggestion that ERK mediates JNK1 activity is not unprecedented, as ERK is known to indirectly increase JNK1 activation in epithelial cells through interactions with kinases upstream from JNK1 (Pedram et al, 1998). Alternatively, nAChR activation could lead to the stimulation of a yet unidentified cascade that leads to increased JNK1 mRNA expression.

There are a number of downstream effectors of JNK that may contribute to the effects of nicotine on contextual FC. In particular, pJNK1 activates a number of transcription factors, such as the jun family, ATF-2, and Elk-1 among others (Gupta et al, 1996; Bogoyevitch and Kobe, 2006). Interestingly, JNK1 contributes to hippocampal long-term depression and short-term synaptic plasticity in the CA1 region, possibly through ATF-2- and c-jun-mediated processes ( $\mathrm{Li}$ et al, 2007). Thus, changes in ATF-2 or cjun activation could contribute to the enhancement of contextual FC by nicotine. In addition, an increase in activated hippocampal Elk-1 and junB has been observed after contextual FC (Sananbenesi et al, 2002; Strekalova et al, 2003) and nicotine administration (Nisell et al, 1997; Nuutinen et al, 2007). Increased levels of pJNK1 after FC paired with nicotine administration could lead to the activation of transcription factors involved in synaptic plasticity and thus an enhanced memory.

Of the various JNK isoforms, JNK1 is the least potent at activating various transcription factors (Gupta et al, 1996; Coffey et al, 2002) but most effective in phosphorylating another downstream effector, microtubule-associated proteins (MAPs) (Chang et al, 2003; Bjorkblom et al, 2005). Although the role of JNK in the activation of MAPs has primarily been studied with regard to neuronal development, MAPs are also important for the synaptic remodeling believed to underlie plasticity in the hippocampus (Muller et al, 2002) and for the consolidation of contextual fear memories (Woolf et al, 1999). MAPs also act as A-kinase anchoring proteins (Diviani and Scott, 2001), which aid in 
the localization of PKA, a kinase extensively implicated in long-term synaptic plasticity and contextual FC (Abel et al, 1997; Nguyen and Woo, 2003). This suggests that another mechanism by which nicotine could enhance contextual FC and synaptic plasticity is by altering PKA signaling through JNK1 phosphorylation of MAPs.

Overall, we show that the effects of nicotine on learning and memory are mediated, at least in part, by JNK1. This is the first demonstration that nicotine and learning interact at the level of gene transcription to produce unique patterns of expression. This effect of nicotine is dependent on $\beta 2$-containing $\mathrm{nAChRs}$ and involves changes in hippocampal function that may enhance consolidation of contextual memories. The implication of JNK1 in the effects of nicotine on cognition suggests a novel avenue of research for understanding the effects of nicotine on learning and synaptic plasticity and the manner by which nAChRs may contribute to addiction and various mental disorders.

\section{ACKNOWLEDGEMENTS}

This research was supported by the National Institute on Drug Abuse (NIDA) grant DA017949 \& DA024787 (T.J.G.). JWK was supported by NIH-NIDA training grant DA07237.

\section{DISCLOSURE}

The authors declare no conflict of interest.

\section{REFERENCES}

Abel T, Nguyen PV, Barad M, Deuel TA, Kandel ER, Bourtchouladze R (1997). Genetic demonstration of a role for PKA in the late phase of LTP and in hippocampus-based long-term memory. Cell 88: 615-626.

Alberini CM (2009). Transcription factors in long-term memory and synaptic plasticity. Physiol Rev 89: 121-145.

Alkondon M, Pereira EF, Albuquerque EX (2003). NMDA and AMPA receptors contribute to the nicotinic cholinergic excitation of CA1 interneurons in the rat hippocampus. J Neurophysiol 90: $1613-1625$.

Athos J, Impey S, Pineda VV, Chen X, Storm DR (2002). Hippocampal CRE-mediated gene expression is required for contextual memory formation. Nat Neurosci 5: 1119-1120.

Bartel DP, Sheng M, Lau LF, Greenberg ME (1989). Growth factors and membrane depolarization activate distinct programs of early response gene expression: dissociation of fos and jun induction. Genes Dev 3: 304-313.

Bennett BL, Sasaki DT, Murray BW, O'Leary EC, Sakata ST, Xu W et al (2001). SP600125, an anthrapyrazolone inhibitor of Jun Nterminal kinase. Proc Natl Acad Sci USA 98: 13681-13686.

Bevilaqua LR, Kerr DS, Medina JH, Izquierdo I, Cammarota M (2003). Inhibition of hippocampal Jun N-terminal kinase enhances short-term memory but blocks long-term memory formation and retrieval of an inhibitory avoidance task. Eur $J$ Neurosci 17: 897-902.

Bjorkblom B, Ostman N, Hongisto V, Komarovski V, Filen JJ, Nyman TA et al (2005). Constitutively active cytoplasmic c-Jun $\mathrm{N}$-terminal kinase 1 is a dominant regulator of dendritic architecture: role of microtubule-associated protein 2 as an effector. J Neurosci 25: 6350-6361.

Bogoyevitch MA, Kobe B (2006). Uses for JNK: the many and varied substrates of the c-Jun N-terminal kinases. Microbiol Mol Biol Rev 70: 1061-1095.
Caggiula AR, Donny EC, Chaudhri N, Perkins KA, Evans-Martin FF, Sved AF (2002). Importance of nonpharmacological factors in nicotine self-administration. Physiol Behav 77: 683-687.

Caldarone BJ, Duman CH, Picciotto MR (2000). Fear conditioning and latent inhibition in mice lacking the high affinity subclass of nicotinic acetylcholine receptors in the brain. Neuropharmacology 39: 2779-2784.

CDC (2002). Cigarette smoking among adults-United States, 2000. MMWR 51: 642-645.

Chang L, Jones Y, Ellisman MH, Goldstein LS, Karin M (2003). JNK1 is required for maintenance of neuronal microtubules and controls phosphorylation of microtubule-associated proteins. Dev Cell 4: 521-533.

Chaudhri N, Caggiula AR, Donny EC, Palmatier MI, Liu X, Sved AF (2006). Complex interactions between nicotine and nonpharmacological stimuli reveal multiple roles for nicotine in reinforcement. Psychopharmacology (Berl) 184: 353-366.

Coffey ET, Smiciene G, Hongisto V, Cao J, Brecht S, Herdegen T et al (2002). c-Jun N-terminal protein kinase (JNK) $2 / 3$ is specifically activated by stress, mediating c-Jun activation, in the presence of constitutive JNK1 activity in cerebellar neurons. J Neurosci 22: 4335-4345.

Crombag HS, Bossert JM, Koya E, Shaham Y (2008). Review. Context-induced relapse to drug seeking: a review. Philos Trans $R$ Soc Lond B Biol Sci 363: 3233-3243.

Davis JA, Gould TJ (2007). Beta2 subunit-containing nicotinic receptors mediate the enhancing effect of nicotine on trace cued fear conditioning in C57BL/6 mice. Psychopharmacology (Berl) 190: $343-352$.

Davis JA, Kenney JW, Gould TJ (2007). Hippocampal alpha4beta2 nicotinic acetylcholine receptor involvement in the enhancing effect of acute nicotine on contextual fear conditioning. J Neurosci 27: 10870-10877.

Davis JA, Porter J, Gould TJ (2006). Nicotine enhances both foreground and background contextual fear conditioning. Neurosci Lett 394: 202-205.

Diergaarde L, de Vries W, Raaso H, Schoffelmeer AN, De Vries TJ (2008). Contextual renewal of nicotine seeking in rats and its suppression by the cannabinoid-1 receptor antagonist Rimonabant (SR141716A). Neuropharmacology 55: 712-716.

Diviani D, Scott JD (2001). AKAP signaling complexes at the cytoskeleton. J Cell Sci 114: 1431-1437.

Fanselow MS, Poulos AM (2005). The neuroscience of mammalian associative learning. Annu Rev Psychol 56: 207-234.

Franklin TR, Wang Z, Wang J, Sciortino N, Harper D, Li Y et al (2007). Limbic activation to cigarette smoking cues independent of nicotine withdrawal: a perfusion fMRI study. Neuropsychopharmacology 32: 2301-2309.

Fujii S, Ji Z, Morita N, Sumikawa K (1999). Acute and chronic nicotine exposure differentially facilitate the induction of LTP. Brain Res 846: 137-143.

Gelinas JN, Banko JL, Peters MM, Klann E, Weeber EJ, Nguyen PV (2008). Activation of exchange protein activated by cyclic-AMP enhances long-lasting synaptic potentiation in the hippocampus. Learn Mem 15: 403-411.

Gould TJ, Feiro O, Moore D (2004). Nicotine enhances trace cued fear conditioning but not delay cued fear conditioning in C57BL/ 6 mice. Behav Brain Res 155: 167-173.

Gould TJ, Higgins SJ (2003). Nicotine enhances contextual fear conditioning in $\mathrm{C} 57 \mathrm{BL} / 6 \mathrm{~J}$ mice at 1 and 7 days post-training. Neurobiol Learn Mem 80: 147-157.

Gould TJ, Lewis MC (2005). Coantagonism of glutamate receptors and nicotinic acetylcholinergic receptors disrupts fear conditioning and latent inhibition of fear conditioning. Learn Mem 12: 389-398.

Gould TJ, Wehner JM (1999). Nicotine enhancement of contextual fear conditioning. Behav Brain Res 102: 31-39. 
Grace AA, Floresco SB, Goto Y, Lodge DJ (2007). Regulation of firing of dopaminergic neurons and control of goal-directed behaviors. Trends Neurosci 30: 220-227.

Greenberg ME, Ziff EB, Greene LA (1986). Stimulation of neuronal acetylcholine receptors induces rapid gene transcription. Science 234: 80-83.

Gupta S, Barrett T, Whitmarsh AJ, Cavanagh J, Sluss HK, Derijard $B$ et al (1996). Selective interaction of JNK protein kinase isoforms with transcription factors. EMBO J 15: 2760-2770.

Hargrove JL, Schmidt FH (1989). The role of mRNA and protein stability in gene expression. FASEB J 3: 2360-2370.

Hernandez PJ, Abel T (2008). The role of protein synthesis in memory consolidation: progress amid decades of debate. Neurobiol Learn Mem 89: 293-311.

Impey S, Smith DM, Obrietan K, Donahue R, Wade C, Storm DR (1998). Stimulation of cAMP response element (CRE)-mediated transcription during contextual learning. Nat Neurosci 1: 595-601.

Ji D, Lape R, Dani JA (2001). Timing and location of nicotinic activity enhances or depresses hippocampal synaptic plasticity. Neuron 31: 131-141.

Kenney JW, Gould TJ (2008a). Modulation of hippocampusdependent learning and synaptic plasticity by nicotine. $\mathrm{Mol}$ Neurobiol 38: 101-121.

Kenney JW, Gould TJ (2008b). Nicotine enhances context learning but not context-shock associative learning. Behav Neurosci 122: 1158-1165.

Kim JJ, Fanselow MS (1992). Modality-specific retrograde amnesia of fear. Science 256: 675-677.

Levy RB, Aoki C (2002). Alpha7 nicotinic acetylcholine receptors occur at postsynaptic densities of AMPA receptor-positive and negative excitatory synapses in rat sensory cortex. J Neurosci 22: 5001-5015.

Li MD, Kane JK, Wang J, Ma JZ (2004). Time-dependent changes in transcriptional profiles within five rat brain regions in response to nicotine treatment. Brain Res Mol Brain Res 132: 168-180.

Li XM, Li CC, Yu SS, Chen JT, Sabapathy K, Ruan DY (2007). JNK1 contributes to metabotropic glutamate receptor-dependent longterm depression and short-term synaptic plasticity in the mice area hippocampal CA1. Eur J Neurosci 25: 391-396.

Muller D, Nikonenko I, Jourdain P, Alberi S (2002). LTP, memory and structural plasticity. Curr Mol Med 2: 605-611.

Nguyen PV, Woo NH (2003). Regulation of hippocampal synaptic plasticity by cyclic AMP-dependent protein kinases. Prog Neurobiol 71: 401-437.

Nisell M, Nomikos GG, Chergui K, Grillner P, Svensson TH (1997). Chronic nicotine enhances basal and nicotine-induced Fos immunoreactivity preferentially in the medial prefrontal cortex of the rat. Neuropsychopharmacology 17: 151-161.

Nuutinen S, Barik J, Jones IW, Wonnacott S (2007). Differential effects of acute and chronic nicotine on Elk-1 in rat hippocampus. Neuroreport 18: 121-126.

Paxinos G, Franklin KBJ (2001). The Mouse Brain in Stereotaxic Coordinates. Academic Press: San Diego, CA.

Pedram A, Razandi M, Levin ER (1998). Extracellular signalregulated protein kinase/Jun kinase cross-talk underlies vascular endothelial cell growth factor-induced endothelial cell proliferation. J Biol Chem 273: 26722-26728.

Petersen DR, Norris KJ, Thompson JA (1984). A comparative study of the disposition of nicotine and its metabolites in three inbred strains of mice. Drug Metab Dispos 12: 725-731.

Piasecki TM (2006). Relapse to smoking. Clin Psychol Rev 26: 196-215. Raybuck JD, Gould TJ (2007). Extracellular signal-regulated kinase $1 / 2$ involvement in the enhancement of contextual fear conditioning by nicotine. Behav Neurosci 121: 1119-1124.
Roberson ED, English JD, Adams JP, Selcher JC, Kondratick C, Sweatt JD (1999). The mitogen-activated protein kinase cascade couples PKA and PKC to cAMP response element binding protein phosphorylation in area CA1 of hippocampus. J Neurosci 19: 4337-4348.

Rose JE, Behm FM, Westman EC, Johnson M (2000). Dissociating nicotine and nonnicotine components of cigarette smoking. Pharmacol Biochem Behav 67: 71-81.

Rudy JW, Huff NC, Matus-Amat P (2004). Understanding contextual fear conditioning: insights from a two-process model. Neurosci Biobehav Rev 28: 675-685.

Sananbenesi F, Fischer A, Schrick C, Spiess J, Radulovic J (2002). Phosphorylation of hippocampal Erk-1/2, Elk-1, and p90-Rsk-1 during contextual fear conditioning: interactions between Erk-1/ 2 and Elk-1. Mol Cell Neurosci 21: 463-476.

Sigurdsson T, Doyere V, Cain CK, LeDoux JE (2007). Long-term potentiation in the amygdala: a cellular mechanism of fear learning and memory. Neuropharmacology 52: 215-227.

Strekalova T, Zorner B, Zacher C, Sadovska G, Herdegen T, Gass P (2003). Memory retrieval after contextual fear conditioning induces c-Fos and JunB expression in CA1 hippocampus. Genes Brain Behav 2: 3-10.

Sweatt JD (2004). Mitogen-activated protein kinases in synaptic plasticity and memory. Curr Opin Neurobiol 14: 311-317.

Tapia L, Kuryatov A, Lindstrom J (2007). Ca2+ permeability of the (alpha4)3(beta2)2 stoichiometry greatly exceeds that of (alpha4)2(beta2)3 human acetylcholine receptors. Mol Pharmacol 71: 769-776.

Turjanski AG, Vaque JP, Gutkind JS (2007). MAP kinases and the control of nuclear events. Oncogene 26: 3240-3253.

USDHHS (1988). The Health Consequences of Smoking: Nicotine Addiction. A Report of the Surgeon General. U.S. Department of Health and Human Services, Publich Health Service, Centers for Disease Control, Disease Prevention and Health Promotion, Office on Smoking and Health: Washington, DC.

Valjent E, Pages C, Herve D, Girault JA, Caboche J (2004). Addictive and non-addictive drugs induce distinct and specific patterns of ERK activation in mouse brain. Eur J Neurosci 19: $1826-1836$.

Vecsey CG, Hawk JD, Lattal KM, Stein JM, Fabian SA, Attner MA et al (2007). Histone deacetylase inhibitors enhance memory and synaptic plasticity via CREB: CBP-dependent transcriptional activation. J Neurosci 27: 6128-6140.

Wada E, Wada K, Boulter J, Deneris E, Heinemann S, Patrick J et al (1989). Distribution of alpha 2, alpha 3, alpha 4, and beta 2 neuronal nicotinic receptor subunit mRNAs in the central nervous system: a hybridization histochemical study in the rat. $J$ Comp Neurol 284: 314-335.

Wehner JM, Keller JJ, Keller AB, Picciotto MR, Paylor R, Booker TK et al (2004). Role of neuronal nicotinic receptors in the effects of nicotine and ethanol on contextual fear conditioning. Neuroscience 129: 11-24.

WHO (2008). WHO report on the global tobacco epidemic: the MPOWER package. 60: 145-149.

Wing VC, Shoaib M (2008). Contextual stimuli modulate extinction and reinstatement in rodents self-administering intravenous nicotine. Psychopharmacology (Berl) 200: 357-365.

Woolf NJ, Zinnerman MD, Johnson GV (1999). Hippocampal microtubule-associated protein-2 alterations with contextual memory. Brain Res 821: 241-249.

Xu W, Orr-Urtreger A, Nigro F, Gelber S, Sutcliffe CB, Armstrong $\mathrm{D}$ et al (1999). Multiorgan autonomic dysfunction in mice lacking the beta2 and the beta4 subunits of neuronal nicotinic acetylcholine receptors. J Neurosci 19: 9298-9305. 